\title{
Okul Yöneticilerinin Dedikodu ve Dedikodu Yönetimine İlişkin Görüşleri
}

\author{
DOI: $10.26466 /$ opus.518272 \\ * \\ Faruk Levent ${ }^{*}-$ Gözde Türkmenoğlu ${ }^{* *}$ \\ * Doç. Dr, Marmara Üniversitesi, Atatürk Eğitim Fakültesi, Kadıköy / İstanbul / Türkiye \\ E-Posta: faruk.levent@marmara.edu.tr \\ ORCID: $\underline{0000-0003-3429-6666}$ \\ ** Doktora Öğrencisi, Marmara Üniversitesi, Eğitim Bilimleri Ens., Kadıköy / İstanbul / Türkiye \\ E-Posta: gozdekarapinar@gmail.com \\ ORCID: $\underline{0000-0002-8665-8860}$
}

Öz

Bu çalışmanın amacı, okul yöneticilerinin okullardaki dedikodu ve dedikodu yönetimine ilişkin görüşlerini incelemektir. Nitel araştırma yöntemlerinden biri olan olgu bilim (fenomenoloji) ile desenlenen bu araştırmanın çalışma grubunu belirlemek üzere amaçl örnekleme yöntemlerinden maksimum çeşitlilik örneklemesi yöntemi kullanılmıştır. Araştırmanın çalışma grubunu, Tekirdağ ili Çorlu ilçesinde bulunan ve devlet okullarında görev yapan 23 okul yöneticisi oluşturmaktadır. Çalışma grubunda yer alan okul yöneticilerinden görüşme yoluyla veri toplanabilmesi için yarı yapılandırılmış görüşme formu geliştirilmiştir. Araştırmada elde edilen veriler içerik analizi tekniği ile çözümlenmiştir. Elde edilen bulgulara göre katılımcıların çoğu, dedikoduyu kişinin arkasından olumsuz konuşma olarak tanımlamıştır ve okulda en fazla öğrenci-öğretmen ilişkileri, haftalık ders programı ve mesleki yeterliliklerin dedikodu konusu yapıldı̆̆ını belirtmiştir. Ayrıca katılımcılar, dedikodu yönetimine ilişkin dedikodu yapanların ikaz edilmesinin, yönetimde şeffaflığın, eleştiriye açıklı̆̆ın ve etkili iletişimin önemine dikkat çekmişlerdir.

Anahtar Kelimeler: Okul yöneticisi, dedikodu, dedikodu yönetimi, söylenti 


\title{
Opinions of School Administrators on Gossip and Gossip Management
}

\begin{abstract}
The purpose of this study was to examine the opinions of school administrators on gossip and gossip management in schools. This research was designed with phenomenology, which is one of the qualitative research methods. In order to determine the study group of the research, maximum variation sampling method, which is one of the purposeful sampling methods, was used. The study group of the research was composed of 23 school administrators who work in public schools in the province of Çorlu, Tekirda Turkey. A semi-structured interview form was developed to collect data from school administrators in the study group. The data obtained from the research were analyzed by content analysis technique. According to the findings, most of the participants explained gossip as negative talk behind someone's back and stated that student-teacher relations, weekly course schedule and professional competences were mostly subject of gossip. In addition, with respect to gossip management, the participants pointed out the importance of giving to gossiper a warning, transparency in management and openness to criticism and communication.
\end{abstract}

Keywords: School administrator, gossip, gossip management, rumor 


\section{Giriş}

Dedikodu ve söylenti, informal iletişim kanalları olarak örgüt içinde etkili olan sosyal olgulardır. Türk Dil Kurumu Sözlüğü'nde (2018) dedikodu "Başkalarını çekiştirmek ve kınamak üzere yapılan konuşma, kov, gıybet, kılükal" olarak tanımlanırken, söylenti "A haber, rivayet" şeklinde açıklanmıştır.

Dedikodu genel olarak ortamda bulunmayan üçüncü bir şahısla ilgili konuşmadır. En az üç kişi, bu eylemin içinde yer aldığı için dedikodu sosyal bir etkinliktir (Wittek ve Wielers, 1998; Kurland ve Pelled, 2000; Dunbar, 2004).

Dedikodu kavramı, toplumda insanlar arasında ve çalışanlar arasında informal yollarla iletilen, kurumla ilgili bilgileri içeren informal iletişimin tümü için kullanılan bir kavramdır (Kumar ve Gopinadhan, 2009, s. 46).

Ting-Toomey'e (1979) göre dedikodu, başka bir kişi hakkında bilgi edinmenin bir yoludur. Bununla birlikte dedikodu bazı durumlarda dedikodu yapan kişi/kişilerin kendi çıkarlarını yönlendirecek manipülatif bir strateji olarak işlev görebilir.

Söylenti ve dedikodu mekanizması örgütte formal iletişim kanallarından daha etkin ve hızlı çalışır, bu sebeple çalışanlar örgütsel haberleri öncelikle informal kanallardan öğrenirler. Her ne kadar dedikodu mekanizmasında taşınan mesajın hızını, kesinliğini, yönünü ya da son halini kestirmek mümkün olmasa da; yapılan çalışmalar bu mekanizmada alınan bilgilerin yaklaşık \%75'inin kesinlik taşıdığını göstermektedir (Bowditch ve Buono, 2005, s. 119).

Dedikodu, pozitif ve negatif olmak üzere iki farklı şekilde gerçekleşmektedir (Turner, Mazur, Wendel ve Winslow, 2003). Pozitif dedikodu, sosyal olarak onaylanmış davranışla ilgili bilgidir. Bu durumda, dedikodu pozitif sosyal yaptırım olarak işlev görür. Negatif dedikodu ise sosyal olarak uygun olmayan davranışla ilgili bilgidir ve insanlar dedikoduyu negatif sosyal bir yaptırım olarak kullanabilirler (Levin, Mody-Desbareau ve Arluke, 1988).

Çalışma yerleri birbirine yakın olan insanlar, çalışma ortamında birbirleriyle etkileşim halinde olanlar, benzer mizaçlı insanlar çoğu zaman aynı dedikodu ağındadır (Rai ve Rai, 2008, s. 55). Çalışanlar arasında 
yoğun iletişimin olduğu iş ortamlarında, ortak grup üyeliği ve sosyal statüsü daha üstte olan bir kişi hakkında negatif dedikodunun ortaya çıkma olasılığ 1 daha fazladır (Ellwardt, Labianca ve Wittek, 2012).

Dedikodunun dört temel özelliği bulunmaktadır: 1) Dedikodu, grup sınırlarını ve normlarını ortaya çıkarır. 2) Dedikodu, başkalarını kontrol altında tutarken ve yaptırımda bulunurken kritik bir rol oynar. 3) Dedikodu, itibarı yönetmede önemli bir etkiye sahiptir. 4) Dedikodu, eğlencelidir ve dolaylı olarak sosyal bağları güçlendirir (Gabriels ve De Backer, 2016).

Dedikodu sosyal karşılaştırma aracıdır ve dedikodu yapan kişi genellikle başkalarının davranışlarını kendi davranışlarıyla kıyaslayıcı konuşmalar yapar (Kurland ve Pelled, 2000; Wert ve Salovey, 2004). Dedikodu çoğu kez etik bir ihlal olduğu zaman meydana gelir ve dedikodu yapan kişi bir kıyaslama yapıp kendini üstün gösterir (Turcotte, 2012, s. 66).

Dedikodu yapılan konular çok boyutludur ve dedikodular kişinin sosyal ve ahlaki değerleriyle ilgili duygu, düşünce ve inançları yansıtır (Litman ve Pezzo, 2005). Dedikodunun en çarpıcı yanı ise her tarafa yayılma ihtimalidir (Ball ve Vincent, 1998).

Örgüt içinde dedikodu davranışı genellikle kelimeler yoluyla aktarılmış olan doğrulanmamış inançları içeren içgüdüsel bir davranıştır. Yöneticiler ve denetçiler, söylentilerin arkasındaki mesajı ararlarsa, söylentileri daha iyi değerlendirebilirler. Bazı söylentiler duyguların sembolik ifadeleridir. Yönetim, örgüt içinde söylenti zincirlerini hiçbir zaman kesemese de; yönetim söylentiyi anlayabilir, yönetebilir ve anlamlı olarak kullanabilir (Akande ve Odewale, 1994).

Dedikodu, yönetimsel ayrıcalıklarla mücadele edilen ve yönetimin örgütü kontrol etme kabiliyetinin zayıflatıldığı bir süreçtir. Yönetim kontrolünün erozyona uğratılmasının bir sonucu olarak çalışanların kendi aralarında oluşturdukları alt kültürler, dedikodu yoluyla bir derece özerklik kazanma imkânı bulurlar (Noon ve Delbridge, 1993, s. 32).

Kurum yöneticileri dedikodu ve söylentiyi tümüyle ortadan kaldıramazlar. Fakat yapmaları gereken, yayılmasını ve etkisini azaltıp dedikodunun olumsuz sonuçlarını en aza indirmektir (Robbins ve Judge, 2014, s. 169). Yöneticiler, dedikoduları etkili bir şekilde yönetmek için şu üç dinamiği kullanırlar (Hernandez, 2015): 
1. Dedikodu yoluyla yöneticiler, bireysel ve kurumsal performansa ilişkin bilgi toplar ve bu bilgiyi kullanırlar.

2. Yöneticiler, dedikodu yoluyla doğrudan yönettikleri bireyler olan ilişkilerini geliştirirler. Böylece yöneticiler zor bilgileri iletmek zorunda kaldıklarında, çalışanlar yöneticileri şeffaf ve güvenilir olarak görürler.

3. Dedikodu yoluyla yöneticiler, bilgiyi iletmek ve yönetim takımının diğer üyeleri için destek kanallarını genişletmek amacıyla çeşitli iletişim kanallarını kullanırlar (yazılı iletişim, yüz yüze, grup toplantıları vb.).

İnformal iletişimin önemli bir bölümünü oluşturan dedikodu, bir örgütte olmazsa olmaz bir iletişim şeklidir. Formal iletişimin tamamlayıcısı olan ve bu bağlamda doğru yönetilmesi gereken bir iletişim ağı olan dedikodu, bir yönetici tarafından etkili bir şekilde kullanılabilir. Dedikoduların tamamen ortadan kaldırılma ihtimali yoktur. Bu nedenle bir yöneticinin kurumda dedikodu ağını etkili şekilde işleterek, dedikoduların hızlı yayılımını avantaja dönüştürmesi gerekir.

Okullar insan ilişkilerinin yoğun olduğu örgütlerdir ve okullarda öğretmen, öğrenci, veli, hizmetli ve diğer personel arasında dedikodu yapılabilmektedir. Bu araştırmanın amacı okul yöneticilerinin, okullardaki dedikodu ve dedikodu yönetimine ilişkin görüşlerini incelemektir. Bu amaç doğrultusunda, aşağıdaki sorulara yanıt aranmıştır:

- Okul yöneticilerinin okul ortamındaki dedikodulara ilişkin görüşleri nasıldır?

- Okul yöneticilerinin dedikodu yönetimine ilişkin görüşleri nasıldir?

\section{Yöntem}

Çalışmanın bu bölümünde; araştırma deseninden, çalışma grubundan, veri toplama aracindan, verilerin toplanmasından ve verilerin analizden bahsedilmektedir. 


\section{Araştırmanın Deseni}

Okul ortamındaki dedikodulara ve dedikodu yönetimine ilişkin okul yöneticilerinin görüşlerini ortaya çıkarmak amaciyla nitel araştırma yönteminin benimsendiği bu çalışmada, olgu bilim (fenomenoloji) araştırma deseni kullanılmıştır. Nitel araştırma, dünyayı görünür kılan bir dizi yorumlayıcı ve önemli uygulamalardan oluşur. Bu uygulamalar dünyayı; alan notları, görüşmeler, sohbetler, fotoğraflar, kayıtlar ve kendine ait kısa notlar da dahil olmak üzere bir dizi betimleme haline dönüştürmektedir. Nitel araştırmacılar, insanların olgulara getirdiği anlamları yorumlamaya ve kavramaya çalışarak konuları doğal ortamlarında inceler (Mertens, 2010, s. 225). Olgu bilim araştırmalarında, araştırmacıların odaklandığı temel nokta, bir olgu ile ilgili katılımc bireylerin belli bir kavram ya da olgu ile ilgili yaşanmış deneyimlerinin belirlenmesidir (Creswell, 2007).

\section{Çalışma Grubu}

Araştırmanın çalışma grubunu, 2016-2017 eğitim-öğretim yılında Tekirdağ ili Çorlu ilçesinde bulunan ve Milli Eğitim Bakanlığı'na bağlı okullarda görev yapan 23 okul yöneticisi oluşturmaktadır. Araştırmaya katılan okul yöneticilerinin 5'i kadın, 18'i erkektir ve katılımcılar ortaokul ve lise düzeyindeki okullarda görev yapmaktadır. Araştırmanın çalışma grubunu belirlemek üzere amaçlı örnekleme yöntemlerinden maksimum çeşitlilik örneklemesi yöntemi kullanılmıştır. Okul yöneticilerinin farklı okul kademeleri ve okul türlerinde görev yapan müdür ve müdür yardımcıları arasından seçilmesi ile çeşitlilik sağlanmaya çalışılmıştır. Araştırmada görüşleri alınan okul yöneticilerinin demografik özelliklerine ilişkin bilgiler Tablo 1'de bulunmaktadır.

Tablo 1. Katılımcı Okul Yöneticilerinin Demografik Özellikleri

\begin{tabular}{|c|c|c|c|c|c|c|c|}
\hline No & Cinsiyet & Branş & Yaş & $\begin{array}{c}\text { Yön. K1- } \\
\text { demi }\end{array}$ & $\begin{array}{c}\text { Öğret. } \\
\text { Kıdemi }\end{array}$ & Okul Türü & $\begin{array}{c}\begin{array}{c}\text { Yönetim Gö- } \\
\text { revi }\end{array} \\
\end{array}$ \\
\hline K1 & Erkek & Felsefe & 43 & $5 \mathrm{y} 11$ & $15 \mathrm{yll}$ & Anadolu Lis. & . Müdür Yard. \\
\hline K2 & Erkek & Coğrafya & 57 & $20 \mathrm{yll}$ & 13 yıl & Anadolu Lis. & Müdür \\
\hline K3 & Kadın & $\begin{array}{l}\text { Türk Dili ve } \\
\text { Edebiyatı }\end{array}$ & 43 & 2 yıl & $21 \mathrm{y} 1 \mathrm{l}$ & Anadolu Lis. & Müdür Yard \\
\hline K4 & Erkek & Felsefe & 55 & 2 yıl & $30 \mathrm{yll}$ & Anadolu Lis. & Müdür Yard \\
\hline
\end{tabular}




\begin{tabular}{|c|c|c|c|c|c|c|c|}
\hline K5 & Erkek & Tarih & 59 & 30 y1l & 6 yil & Anadolu Lis. & Müdür \\
\hline K6 & Erkek & $\begin{array}{l}\text { Türk Dili ve } \\
\text { Edebiyatı }\end{array}$ & 40 & 2 yıl & 17 yıl & Anadolu Lis. & Müdür Yard \\
\hline K7 & Erkek & $\begin{array}{l}\text { Türk Dili ve } \\
\text { Edebiyatı }\end{array}$ & 36 & 4 yıl & 8 yil & Anadolu Lis. & Müdür Yard \\
\hline K8 & Erkek & $\begin{array}{l}\text { Din Kül. ve Ah- } \\
\text { lak Bilgisi }\end{array}$ & 54 & $27 \mathrm{y} 1 \mathrm{l}$ & 2 yil & Anadolu Lis. & Müdür \\
\hline K9 & Erkek & Tarih & 57 & $20 \mathrm{y} 1 \mathrm{l}$ & $10 \mathrm{yll}$ & Anadolu Lis. & Müdür \\
\hline K10 & Kadın & Bilgisayar & 31 & 4 yil & 6 yil & Anadolu Lis. & Müdür Yard \\
\hline K11 & Erkek & İngilizce & 38 & 5 y1l & 11 yıl & Anadolu Lis. & Müdür Yard \\
\hline K12 & Erkek & Beden Eğitimi & 53 & 16 yil & 14 yıl & Anadolu Lis. & Müdür Yard \\
\hline K13 & Kadın & İngilizce & 32 & 6 y1l & 3 yil & Anadolu Lis. & Müdür Yard \\
\hline K14 & Erkek & İngilizce & 40 & $14 \mathrm{y} 1 \mathrm{l}$ & $5 \mathrm{y} 1 \mathrm{l}$ & Anadolu Lis. & Müdür Yard \\
\hline K15 & Erkek & İngilizce & 36 & 4 y1l & 10 yıl & Ortaokul & Müdür Yard \\
\hline K16 & Kadın & İngilizce & 37 & 3 y1l & 9 yil & Ortaokul & Müdür Yard \\
\hline K17 & Erkek & Sosyal Bilgiler & 40 & 13 yıl & 4 yil & Ortaokul & Müdür Yard \\
\hline K18 & Kadın & Matematik & 52 & 3 y1l & $20 \mathrm{yll}$ & Anadolu Lis. & Müdür Yard \\
\hline K19 & Erkek & Kimya & 47 & 11 yıl & 12 yıl & Anadolu Lis. & Müdür \\
\hline K20 & Erkek & Tarih & 38 & 4 yıl & 14 yıl & Fen Lisesi & Müdür Yard \\
\hline K21 & Erkek & Görsel Sanatlar & 38 & 7 yıl & 10 yıl & Fen Lisesi & Müdür Yard \\
\hline K22 & Erkek & Matematik & 50 & $10 \mathrm{y} 1 \mathrm{l}$ & $15 \mathrm{yll}$ & Fen Lisesi & Müdür Yard \\
\hline K23 & Erkek & Kimya & 53 & $17 \mathrm{yll}$ & 11 yıl & Fen Lisesi & Müdür Yard \\
\hline
\end{tabular}

\section{Veri toplama aracı ve verilerin toplanması}

Olgu bilim araştırmalarında başlıca veri toplama aracı görüşmedir (Yıldırım ve Şimşek, 2013; Christensen, Johnson ve Turner, 2015; Gliner, Morgan ve Leech, 2015). Coleman (2012) görüşmenin, sosyal bilimler alanında yapılan araştırmalarda kullanılan en yaygın veri toplama yöntemi olduğunu belirtmiştir. Görüşme; bireylerin deneyimlerine, tutumlarına, görüşlerine, şikâyetlerine, duygularına ve inançlarına ilişkin bilgi elde etmede başarılı bir yöntemdir (Briggs, 1986; akt. Yıldırım ve Şimşek, 2013, s.105). Görüşme; bireylerin çeşitli konulardaki görüş, tutum, bilgi ve davranışları ile bunların olası nedenleri arasındaki ilişkinin öğrenilmesinde kullanılan en kestirme yoldur. Görüşmede araştırmacı netleşmeyen konularla ilgili anında soru sorma olanağı da bulabilmektedir. Araştırmacı, söylenenlerin yüzeysel anlamının yanı sıra derin anlamlarıyla ilgili de ipuçları yakalayabilir (Karasar, 2015, s.166).

$\mathrm{Bu}$ araştırmada veri toplama aracı olarak yarı yapılandırılmış görüşme formu kullanılmıştır. Yarı yapılandırılmış görüşme formu, görüşme 
sırasında araştırmacıya yöneltilecek sorular veya konular listesini kapsamaktadır (Yıldırım ve Şimşek, 2013). Yarı yapılandırılmış görüşme formu, görüşme süresince farklı sorularla konunun açılmasına, çeşitli boyutların ortaya çıkmasına ve konu hakkında yeni fikirlere ulaşılmasına katkı sağlamaktadır (Merriam, 2013, s.193). Yarı yapılandırılmış görüşme formu oluşturulurken öncelikle konu ile ilgili alanyazın incelenmiştir. Alanyazın incelenmesinden sonra oluşturulan yarı yapılandırılmış görüşme formu, önce eğitim yönetimi alanında uzman iki öğretim üyesine sunulmuştur. Uzman görüşlerinin ardından yarı yapılandırılmış görüşme formunda çeşitli düzenlemeler yapılmıştır. Ardından, yarı yapılandırılmış görüşme formu pilot uygulama olarak iki okul yöneticisine uygulanmıştır. Pilot uygulama sonrasında yarı yapılandırılmış görüşme formuna son şekli verilmiştir. Yarı yapılandırılmış görüşme formu iki bölümdür. İlk bölümde katılımcıların demografik özelliklerine yönelik sorular bulunmaktadır. İkinci bölümde ise katılımcların okullardaki dedikodu ve dedikodu yönetimine ilişkin görüşlerine yönelik sorular yer almaktadır.

$\mathrm{Bu}$ araştırmada görüşmelerin organize edilmesi için öncelikle okul müdüründen izin talep edilmiş, okul müdürlerinin izin verdiği okullarda araştırmaya gönüllülük esasına göre katılan okul yöneticilerinden randevu talep edilmiş, uygun ortam ve zamanda görüşmeler yapılmıştır. Görüşmelere başlamadan önce araştırmanın amacı ve görüşmenin amacı katılımclara açıkça ifade edilmiştir. Ayrıca kurum ve şahıs isimlerinin hiçbir şekilde geçmeyeceği ve verilerin bilimsel amaçlar dışında kullanılmayacağı belirtilmiştir. Görüşmeler, 30 ile 45 dakika arasında değişen sürelerde gerçekleştirilmiştir.

\section{Verilerin Analizi}

Araştırmada elde edilen verilerin çözümlenmesinde içerik analizi tekniği kullanılmıştır. İçerik analizinde amaç, toplanan verileri açıklayabilecek kavramlara ve ilişkilere ulaşmaktır. Kodlama; verilerin içerik analizine tabi tutulması, yani veriler arasında yer alan anlamlı bölümlere (bir sözcük, cümle, paragraf gibi) isim verilmesi sürecidir (Yıldırım ve Şimşek, 2013, s.255).

Araştırmada yapılan görüşmelerde, okul yöneticilerinin sorulara verdikleri cevaplar dogrultusunda temalar ve kodlar oluşturulmuştur. Ve- 
riler birbiriyle uyumlu olacak s,ekilde sınıflandırılarak, alt temalar belirlenmiştir. İlk taslak bittikten sonra analiz tekrar gözden geçirilerek, tekrarlayan veya birbiriyle uyumlu olmayan temalar yeniden sınıflandırılmıştır. Görüşme yapılan okul yöneticileri tarafından dile getirilen görüş ve ifadelerin hangi okul yöneticisine ait olduğunu belirtmek için doğrudan alıntıların sonlarına (K1, K2... vb.) biçiminde kodlar eklenmiştir.

\section{Bulgular}

Katılımcı okul yöneticilerinin okullarda dedikodu ve dedikodu yönetimine ilişkin görüşleri; dedikodunun anlamı, dedikodu konuları, dedikodunun sonuçları ve dedikodunun yönetimi için yapılması gerekenler temaları altında toplanmıştır.

\section{Dedikodunun Anlamına İlişkin Bulgular}

Dedikodunun anlamına ilişkin okul yöneticilerinin görüşleri Tablo 2'de verilmiştir.

Okul yöneticilerinin dedikodunun anlamına ilişkin görüşleri; dedikodu kişinin arkasından olumsuz konuşmalardır (15/23), dedikodu kişinin arkasından yapılan olumlu ya da olumsuz yorumlardır (6/23), dedikodu laf taşımadır (1/23) ve dedikodu bir tür bilgi akışıdır (1/23) alt temaları altında toplanmıştır.

Tablo 2. Okul Yöneticilerinin Dedikodunun Anlamına İlişkin Görüşleri

\begin{tabular}{|c|c|c|c|}
\hline Tema & Alt Temalar & (f) & Katılımcılar \\
\hline \multirow{4}{*}{$\begin{array}{l}\text { Dedikodunun } \\
\text { Anlamı }\end{array}$} & $\begin{array}{l}\text { Kişinin arkasından } \\
\text { olumsuz konuşmalar }\end{array}$ & 15 & $\begin{array}{l}\mathrm{K}_{1} \mathrm{~K}_{4} \mathrm{~K}_{5} \mathrm{~K}_{7} \mathrm{~K}_{8} \mathrm{~K}_{12} \mathrm{~K}_{14} \mathrm{~K}_{15} \mathrm{~K}_{16} \mathrm{~K}_{17} \mathrm{~K}_{18} \\
\mathrm{~K}_{19} \mathrm{~K}_{20} \mathrm{~K}_{21} \mathrm{~K}_{23}\end{array}$ \\
\hline & $\begin{array}{l}\text { Kişinin arkasından } \\
\text { yapılan olumlu ya da } \\
\text { olumsuz yorumlar }\end{array}$ & 6 & $\mathrm{~K}_{3} \mathrm{~K}_{6} \mathrm{~K}_{9} \mathrm{~K}_{10} \mathrm{~K}_{13} \mathrm{~K}_{22}$ \\
\hline & Laf taşıma & 1 & $\mathrm{~K}_{2}$ \\
\hline & Bilgi akışı & 1 & $\mathrm{~K}_{11}$ \\
\hline
\end{tabular}

Bu temaya ilişkin katılımcı görüşlerinden bazıları şöyledir:

"Insanın yüzüne karşı konuşulamayan her şey, olumsuz konuşmalardır." (K12) 
"İnsanların birbirlerinin arkasından açıklarını dile getirme gibi olumsuz konuşmalar veya yapıcı, olumlu konuşmalardır." (K13)

"Dedikodu, laf taşıma ve laf götürme gibi bir şeydir." (K2)

\section{Dedikodunun Konularına İlişkin Bulgular}

Okullarda yapılan dedikodunun konularına ilişkin okul yöneticilerinin görüşleri Tablo 3'te verilmiştir.

Tablo 3. Okul Yöneticilerinin Dedikodu Konularnna İlişkin Görüşleri

\begin{tabular}{|c|c|c|c|c|}
\hline Tema & Alt Temalar & Kodlar & (f) & Katılımcilar \\
\hline \multirow{8}{*}{$\begin{array}{l}\text { Dedi- } \\
\text { kodu } \\
\text { Konuları }\end{array}$} & Öğrenciler & Öğretmen-öğrenci ilişkileri & 12 & $\begin{array}{l}K_{1} K_{4} K_{6} K_{7} K_{8} K_{9} K_{10} \\
K_{12} K_{13} K_{15} K_{19} K_{23} \\
\end{array}$ \\
\hline & \multirow{6}{*}{$\begin{array}{l}\text { Öğretmen- } \\
\text { ler }\end{array}$} & Haftalık ders programları & 10 & $\begin{array}{l}\mathrm{K}_{1} \mathrm{~K}_{2} \mathrm{~K}_{6} \mathrm{~K}_{7} \mathrm{~K}_{8} \mathrm{~K}_{10} \mathrm{~K}_{11} \\
\mathrm{~K}_{14} \mathrm{~K}_{16} \mathrm{~K}_{17}\end{array}$ \\
\hline & & Mesleki yeterlilikler & 10 & $\begin{array}{l}\mathrm{K}_{2} \mathrm{~K}_{3} \mathrm{~K}_{4} \mathrm{~K}_{5} \mathrm{~K}_{6} \mathrm{~K}_{7} \mathrm{~K}_{11} \\
\mathrm{~K}_{13} \mathrm{~K}_{18} \mathrm{~K}_{20}\end{array}$ \\
\hline & & Özel hayat & 6 & $\mathrm{~K}_{1} \mathrm{~K}_{3} \mathrm{~K}_{4} \mathrm{~K}_{6} \mathrm{~K}_{7} \mathrm{~K}_{18}$ \\
\hline & & Görev ve sorumlulukları & 6 & $\mathrm{~K}_{6} \mathrm{~K}_{7} \mathrm{~K}_{11} \mathrm{~K}_{20} \mathrm{~K}_{21} \mathrm{~K}_{22}$ \\
\hline & & Kişisel özellikleri & 3 & $\mathrm{~K}_{8} \mathrm{~K}_{18} \mathrm{~K}_{21}$ \\
\hline & & Maddi durumları & 3 & $\mathrm{~K}_{2} \mathrm{~K}_{3} \mathrm{~K}_{6}$ \\
\hline & $\begin{array}{l}\text { Okul } \\
\text { yöneticileri }\end{array}$ & $\begin{array}{l}\text { Öğretmenlerin kayırılması } \\
\text { /Adaletsiz uygulamalar }\end{array}$ & 10 & $\begin{array}{l}\mathrm{K}_{1} \mathrm{~K}_{6} \mathrm{~K}_{7} \mathrm{~K}_{8} \mathrm{~K}_{9} \mathrm{~K}_{11} \mathrm{~K}_{14} \\
\mathrm{~K}_{20} \mathrm{~K}_{21} \mathrm{~K}_{23}\end{array}$ \\
\hline
\end{tabular}

Araştırmaya katılan okul yöneticilerin yarısı (12/23), okulda öğrencilerle ilgili olarak öğrenci-öğretmen ilişkilerinin dedikodu konusu yapıldığını belirtmiştir. Katılımclara göre öğretmenlerle ilgili; haftalık ders programları (10/23), mesleki yeterlilikler (10/23), özel hayat (6/23), görev ve sorumluluklarını yerine getirip getirmeme (6/23), maddi durum (3/23) ve kişisel özellikler (3/23) konularında dedikodu yapıldığını ifade etmişlerdir. Ayrıca katılımcı görüşlerine göre okul yöneticilerinin de bazı öğretmenleri kayırması ve adaletsiz uygulamalarının dedikodu konusu olduğu ön plana çıkmaktadır. Bu temaya ilişkin katılımcı görüşlerinden bazıları şöyledir: 
“Öğretmenlerin özel hayatları, öğrenci-öğretmen ilişkileri, idareye yönelik konuşmalar, ders programlarl; idare torpil yapıyor, diğer öğretmenler niye bahçe nöbeti tutmuyor gibi konuşmalar olmaktadır." (K6)

"Öğretmenler birbiri hakkında konuşur. Aynı branştan ise ders işleyişi, mesleki yeterliği hakkında konuşur çoğu zaman." (K7)

"Yöneticiler eleştirilir, ders programı konusunda adaletsiz davrandığı konuşulur, öğrenciler arasında öğretmenlerin giyim kuşamı, konuşma tarzları dikkat çeker, öğretmeni konuşurken bunlar ele alınır." (K8)

"Ders programları, iki öğretmenin başka bir öğretmenin ders programı hakkında konuşması, ona iyi program yapmışlar, bana kötü demesi. Öğretmenlerin okul idaresi tarafindan kayırnlması dedikodusu çok olmaktadır." (K14)

"Okulda genellikle öğretmenlerin görevlerini ifa etmeleri ve sorumluluklart ile ilgili dedikodular olmaktadır." (K21)

"Özel hayatla ilgili, mesleki yeterlikleri, maddi koşulları, makam mevki gibi durumlar ile ilgili konuşmalar dedikodu malzemesi olmaktadır." (K3)

\section{Dedikodunun Sonuçlarına İlişkin Bulgular}

Okullardaki dedikodunun sonuçlarına ilişkin okul yöneticilerinin görüşleri Tablo 4'te verilmiştir.

Tablo 4. Okul Yöneticilerinin Dedikodunun Sonuçlarına İlişkin Görüşleri

\begin{tabular}{|c|c|c|c|c|}
\hline Tema & $\begin{array}{l}\text { Alt Te- } \\
\text { malar }\end{array}$ & Kodlar & (f) & Katılımcılar \\
\hline \multirow{7}{*}{$\begin{array}{l}\text { Dedikodunun } \\
\text { Sonuçları }\end{array}$} & \multirow{3}{*}{ Olumlu } & Özeleştiri imkanı & 10 & $\begin{array}{l}\mathrm{K}_{3} \mathrm{~K}_{4} \mathrm{~K}_{5} \mathrm{~K}_{6} \mathrm{~K}_{7} \mathrm{~K}_{8} \mathrm{~K}_{11} \mathrm{~K}_{13} \\
\mathrm{~K}_{16} \mathrm{~K}_{23}\end{array}$ \\
\hline & & $\begin{array}{l}\text { Sorunların fark } \\
\text { edilmesi }\end{array}$ & 8 & $\mathrm{~K}_{2} \mathrm{~K}_{4} \mathrm{~K}_{5} \mathrm{~K}_{9} \mathrm{~K}_{14} \mathrm{~K}_{16} \mathrm{~K}_{19} \mathrm{~K}_{23}$ \\
\hline & & Eğlence & 2 & $\mathrm{~K}_{1} \mathrm{~K}_{12}$ \\
\hline & \multirow{4}{*}{ Olumsuz } & Gruplaşma / Çatışma & 17 & $\begin{array}{l}\mathrm{K}_{1} \mathrm{~K}_{2} \mathrm{~K}_{3} \mathrm{~K}_{4} \mathrm{~K}_{5} \mathrm{~K}_{6} \mathrm{~K}_{7} \mathrm{~K}_{8} \mathrm{~K}_{9} \\
\mathrm{~K}_{10} \mathrm{~K}_{11} \mathrm{~K}_{13} \mathrm{~K}_{14} \mathrm{~K}_{17} \mathrm{~K}_{18} \mathrm{~K}_{20} \\
\mathrm{~K}_{21}\end{array}$ \\
\hline & & $\begin{array}{l}\text { Öğretmenlerde perfor- } \\
\text { mans / motivasyon } \\
\text { düşüklüğü }\end{array}$ & 9 & $\begin{array}{l}\mathrm{K}_{5} \mathrm{~K}_{10} \mathrm{~K}_{12} \mathrm{~K}_{15} \mathrm{~K}_{16} \mathrm{~K}_{17} \mathrm{~K}_{21} \\
\mathrm{~K}_{22} \mathrm{~K}_{23}\end{array}$ \\
\hline & & Güvensizlik & 3 & $\mathrm{~K}_{7} \mathrm{~K}_{20} \mathrm{~K}_{21}$ \\
\hline & & İtibarsızlaşma & 3 & $\mathrm{~K}_{3} \mathrm{~K}_{6} \mathrm{~K}_{8}$ \\
\hline
\end{tabular}


Tablo 4'te görüldüğü üzere katılımcı okul yöneticileri, dedikodunun olumsuz sonuçları olduğu gibi bazı olumlu sonuçlarının da olabileceğini ifade etmiştir.

Dedikoduya olumlu açıdan bakan katılımcılar; dedikodunun kişinin kendini geliştirmesi yönünde bir özeleştiri kaynağı olduğunu (10/23), dedikodunun sorunun fark edilmesini sağladığını (8/23) ve dedikodunun eğlenceli bir aktivite olduğunu (2/23) belirtmişlerdir. Dedikodunun olumsuz sonuçlarına ilişkin katılımcı okul yöneticileri ise dedikodunun okul ortamında gruplaşmalara neden olduğu (17/23), dedikodunun öğretmenlerde performans/motivasyon düşüklüğüne neden olduğu (9/23), dedikodunun okul içinde güvensizlik ortamı oluşturduğu (3/23) ve dedikoduların öğretmenlerin itibarsızlaşmasına neden olduğu (3/23) şeklinde görüş bildirmiştir. Bu temaya ilişkin katılımcı görüşlerinden bazıları şöyledir:

"Bir dedikodu varsa sıkıntı vardır. Dedikodu sorunların ortaya çımasını sağlaması açısından faydalıdır denebilir." (K9)

"Dedikodular, sorunlar hakkında ipucu verir. Çünkü ateş olmayan yerden duman çıkmaz." (K23)

"Dedikodu, kişinin özeleştiri yapmasın sağlar. Böylece kişi kendini geliştirebilir." (K6).

"İnsanların deşarj olmasını sağlar. Bu açıdan eğlenceli bir şeydir." (K1).

"Dedikodular özellikle öğrenciler arasında öğretmenleri itibarsizlaştırıyor." (K6)

"Dedikodular, gruplaşmalara neden olur. Insanlarm motivasyonunu düşürebilir." (K10).

"Dedikodu, öğretmenler arası ilişkileri bozabilir, bu nedenle de gruplaşma olur öğretmenler arasında." (K9)

"Dedikodu olunca okulda bir şekilde huzursuzluk olur. Dedikoduyu ben söyledim diyen de olmadığı için çıkış noktası bilinmediğinden okulda güvensiz bir ortam oluşur." (K7) 


\section{Dedikodu Yönetimine İlişkin Bulgular}

Okul yöneticilerinin dedikodu yönetimine ilişkin görüşleri Tablo 5'te verilmiştir.

Tablo 5. Okul Yöneticilerinin Dedikodularn Yönetimine İlişkin Görüşleri

\begin{tabular}{|c|c|c|c|}
\hline Tema & Alt Temalar & (f) & Katılımcilar \\
\hline \multirow{12}{*}{$\begin{array}{l}\text { Dedi- } \\
\text { kodu } \\
\text { Yönetimi }\end{array}$} & $\begin{array}{l}\text { Dedikodu yapanları ikaz et- } \\
\text { mek }\end{array}$ & 18 & $\begin{array}{l}\mathrm{K}_{2} \mathrm{~K}_{3} \mathrm{~K}_{4} \mathrm{~K}_{5} \mathrm{~K}_{6} \mathrm{~K}_{7} \mathrm{~K}_{8} \mathrm{~K}_{9} \mathrm{~K}_{10} \mathrm{~K}_{11} \mathrm{~K}_{12} \\
\mathrm{~K}_{13} \mathrm{~K}_{14} \mathrm{~K}_{17} \mathrm{~K}_{18} \mathrm{~K}_{19} \mathrm{~K}_{20} \mathrm{~K}_{22}\end{array}$ \\
\hline & Yönetimde şeffaflık / açıklık & 11 & $\mathrm{~K}_{2} \mathrm{~K}_{3} \mathrm{~K}_{4} \mathrm{~K}_{5} \mathrm{~K}_{7} \mathrm{~K}_{9} \mathrm{~K}_{11} \mathrm{~K}_{15} \mathrm{~K}_{16} \mathrm{~K}_{20} \mathrm{~K}_{21}$ \\
\hline & Eleştiriye / İletişime açıklık & 10 & $\mathrm{~K}_{1} \mathrm{~K}_{2} \mathrm{~K}_{3} \mathrm{~K}_{5} \mathrm{~K}_{8} \mathrm{~K}_{9} \mathrm{~K}_{13} \mathrm{~K}_{20} \mathrm{~K}_{22} \mathrm{~K}_{23}$ \\
\hline & Arabuluculuk & 10 & $\mathrm{~K}_{2} \mathrm{~K}_{4} \mathrm{~K}_{6} \mathrm{~K}_{7} \mathrm{~K}_{11} \mathrm{~K}_{12} \mathrm{~K}_{17} \mathrm{~K}_{20} \mathrm{~K}_{21} \mathrm{~K}_{23}$ \\
\hline & Sir saklamak & 6 & $\mathrm{~K}_{2} \mathrm{~K}_{8} \mathrm{~K}_{11} \mathrm{~K}_{14} \mathrm{~K}_{18} \mathrm{~K}_{22}$ \\
\hline & $\begin{array}{l}\text { Bazı dedikoduları } \\
\text { görmezden gelmek }\end{array}$ & 6 & $\mathrm{~K}_{5} \mathrm{~K}_{6} \mathrm{~K}_{9} \mathrm{~K}_{13} \mathrm{~K}_{20} \mathrm{~K}_{21}$ \\
\hline & Formal iletişimi arttırmak & 6 & $\mathrm{~K}_{15} \mathrm{~K}_{18} \mathrm{~K}_{19} \mathrm{~K}_{20} \mathrm{~K}_{21} \mathrm{~K}_{22}$ \\
\hline & Adaletli davranmak & 5 & $\mathrm{~K}_{2} \mathrm{~K}_{8} \mathrm{~K}_{12} \mathrm{~K}_{15} \mathrm{~K}_{17}$ \\
\hline & Güven ortamı oluşturmak & 4 & $\mathrm{~K}_{1} \mathrm{~K}_{4} \mathrm{~K}_{8} \mathrm{~K}_{11}$ \\
\hline & Zamanında bilgilendirmek & 4 & $\mathrm{~K}_{4} \mathrm{~K}_{15} \mathrm{~K}_{5} \mathrm{~K}_{11}$ \\
\hline & $\begin{array}{l}\text { İstişare/Kararlara katılım } \\
\text { sağlamak }\end{array}$ & 1 & $\mathrm{~K}_{5}$ \\
\hline & Boş vakitleri azaltmak & 1 & $\mathrm{~K}_{6}$ \\
\hline
\end{tabular}

Tablo 5'te görüldüğü üzere okul yöneticilerinin dedikodunun yönetimine ilişkin görüşleri; dedikodu yapanları ikaz etmek (18/23), yönetimde şeffaflık/açıklık (11/23), eleştiriye/iletişime açıklık (10/23), arabuluculuk (10/23), sır saklamak (6/23), bazı dedikoduları görmezden gelmek (6/23), formal iletişimi arttırmak (6/23), adaletli davranmak (5/23), güven ortamı oluşturmak (4/23), zamanında bilgilendirmek (4/23), istişare/kararlara katılım sağlamak (1/23) ve boş vakitleri azaltmak (1/23) şeklinde ortaya konmuştur. Bu temaya ilişkin katılımcı görüşlerinden bazıları şöyledir:

"Müdür yardımcılarımdan genellikle ketum olmaların isterim. Eskilerin bir sözü vardır. Bunu hem yöneticilere hem öğretmenlere dile getiririm: Şüyuu vukuundan beterdir. Yani, dedikodusu gerçekleşmesinden beterdir. Yöneticinin sır saklamasını bilmesi lazım." (K8) 
"Boş vakit daha çok dedikodu yaratıyor. Öğretmenlere sorumluluk vermek, sınav analizi, kulüp çalışması yaptırmak dedikoduları azaltır. Çok ögretmen atandı. Ders sayısı azaldı, boşluklar oldu ders programlarında. Boş derste öğretmenler odasinda oturunca dedikodular oluyor." (K6)

"Söylentiler ve dedikoduların doğruluk payı olanlar varsa değerlendirip düzeltmek gerekir. Dedikodu yapanlar her zaman olacaktır. Onlarn da zaman zaman ikaz ederiz." (K22)

"Şeffaf olunmalı. Adalet sağlanmalı. Her şey göz önündeyse dedikodu olmaz. Ayrıca üsluba dikkat etmek, iletişim kanalların açık tutmak gerekir." (K2)

"Anlaşamayan iki arkadaşı uzlaştırmak için arabuluculuk yapmıştım. Benim vesilemle araları düzeldi, şimdi çok yakın arkadaşlar." (K23)

"Yönetimde alınan kararlarm istişare ve katılım sağlanarak alınması ve bilgilendirmenin sık sık yapılması dedikodunun yönetilmesinde faydalı olur. Birlikte karar verme dedikoduyu önler." (K5)

"Tüm bilgi akışı sürekli ve şeffaf olmalı. Gerektiğinde her zaman tüm çalışanlarla bir araya gelinmeli ve zamanında bilgilendirme yapılmal. Formal kanallar açık tutulmall. Ayrıca WhatsApp ve mail gibi yollarla bilgi akışı daha kolay sağlanmakta." (K15)

"Öğretmenler arasinda herkese eşit mesafede durmak ve adaletli davranmak gerekiyor." (K17)

"Toplantılarda her şeyi tüm gerçekliğiyle ortaya dökmekten yanayım. Birinden duyduğumu söylemeden bunun aslının olup olmadığıı öğrenmeye çalışırım. Söz konusu gerçek başkaysa, o dedikoduyu sonlandırmak için gerçekleri ortaya koyarım." (K4)

\section{Tartışma}

Araştırmaya katılan okul yöneticileri dedikoduyu; laf taşıma, kişinin arkasından olumsuz konuşma, bilgi akışı ve ortamda bulunmayan bir kişi için yapılan olumlu ya da olumsuz yorumlar olarak tanımlamaktadır. Foster'a (2004) göre dedikodu, üçüncü bir kişi hakkında değerlendirici bir tavırla iletilen kişisel bilgidir. Brock ve Grady'e (2009, s.35) göre dedikodu yapılmasının genel olarak nedeni insanların "bilgi sahibi olmak" ve bilgileri ilk paylaşan kişi olmak istemeleridir. Ancak bazı dedikoducular 
kötü niyetli olabilirler; bu kişilerin amaçları intikam almak, başka bir kişinin itibarına ve güvenilirliğine zarar vermektir. Dedikodunun amacı intikam olduğunda mağdurun itibar, liderlik ya da kariyeri zarar gördüğü zaman dedikodu yapan kişi hedefine ulaşmış olur.

Dedikodulara yaygin olarak atfedilen olumsuz anlam aslında doğru değildir (Ben-Ze'ev, 1994, s.1). Dedikodu yoluyla birisi tarafindan anlaşılmış olma ve diğerleriyle ayn gemide olma hissi tadılır. Bu sosyal destek deneyimi, gerilimin hafiflemesine yol açabilir. Dedikodu yoluyla kişi, insanların benzer problemlerle nasıl baş ettiğini öğrenebilir. Dedikodu, özel bir eylemle değiştirilemeyen stresli durumlar olduğunda eğlence amaciyla kullanılabilir (Kakar, 2013, s.55-56). Dedikodu, arkadaşlara iletildiğinde ve pozitif olduğunda sosyal bir tutkaldır. Dedikodu ilişkisel bağlantılar oluşturur. Arkadaşlar arasındaki dedikodu güven ve bağll1ık inşa eder (Turner, Mazur, Wendel ve Winslow, 2003). Bununla birlikte dedikodu tarihsel olarak kötü bir şöhrete sahiptir. Dedikoduculara karşı toplumsal tutumlar büyük çoğunlukla olumsuzdur. Bu durum, popüler kültürde dedikodular hakkında yapılan yorumlarda da görülebilir. Dedikodu yoluyla iletilen bilgiler sayesinde insanlar, diğer kişilerin güvenilirliğini ve güvenilmezliğini anlayabilirler. Bu şekilde dedikodu insanların ilişkilerini düzenlemelerine yardımcı olabilir (Peters ve Kashima, 2015). Bu araştırmada katılımcı okul yöneticilerine göre okuldaki dedikodular; dedikodu yapan kişilere eğlence sağlamakta (2/23), sorunların fark edilmesine (8/23) ve özeleştiri yapabilmeye (10/23) imkân vermektedir.

Dedikodu, resmi bilgilerin iletilmesine yardımcı olabilir. Dedikodu bazı durumlarda, risk ve bilgi paylaşımı yoluyla sadakati sağlamlaştırarak kişilerarası ilişkileri güçlendirebilir. Dedikodu, çalışanların bireysel görevlerini etkili bir şekilde yerine getirmek için ihtiyaç duydukları karşılıklı anlayışın oluşmasına yardımcı olabilir. Kuralların, değerlerin ve normların iletilmesini sağlayabilir; örgütsel gelenek ve kültürün yayılmasını kolaylaştırabilir. Dedikodu yoluyla iletilen bilgiler, daha önce grup için belirsiz olan konular hakkında bir açılama sunabilir ve böylece güvensizlik ve kaygı duygularını azaltabilir. Bununla birlikte dedikodu sosyal değişim için etkili bir araç olabilir (Noon ve Delbridge, 1993, s.33). Örneğin çalışanlara daha hızlı bilgi ulaştırma, uygulanması düşünülen 
yönetim stratejileri için çalışanların tepkilerini test etme veya ölçme şeklinde dedikodu etkili rol oynayabilir (Michelson ve Mouly, 2004).

Araştırmalar dedikodunun sadece zikzaklı, güvenilmez bir araç olmadığını göstermektedir. Dedikodu, formal iletişim sisteminin taşıdığı bilgiye oranla daha fazla bilgi taşır ve formal kanalın yavaşlı̆̆ından çok daha hızlı hareket eder (Rai ve Rai, 2008, s.55). Dedikodu yapmak, sosyal bir uyum duygusu uyandırmakta ve çalışanların örgütsel ve kişisel olaylarla ilgili umutlarını, korkularını ve endişelerini dile getirmelerini sağlamaktadır (Burke ve Wise, 2003). Dedikodu ve söylentiler, aynı düzeydeki çalışanların ortak karar almalarını sağlar (Aydın, 2007, s.40). Dedikodu hem diğer üyelerle bağ kurmanın, grup sadakatinin sergilenmesi hem de gruba dahil olma oranını arttırmanın ideal bir yoludur (Turcotte, 2012; Granecki, 2014).

$\mathrm{Bu}$ araştırmada katılımcılara göre okulda dedikodunun bazı olumlu sonuçları olmakla birlikte olumsuz sonuçları da bulunmaktadır. Katılımcılar dedikodunun; öğretmenler arasında gruplaşmalara ve çatışmalara neden olduğunu (17/23), öğretmen ve okul yöneticilerinin performans ve motivasyonunu düşürdügünü (9/23), güvensizlik ortamı yarattığını (3/23) ve öğretmenleri itibarsızlaştırdığını belirtmiştir. Kakar'a (2013) göre dedikodu birinin diğer bir kişi hakkında düşüncesini yönlendirmek ya da birinin itibarını düşürmek için kullanılabilmektedir (s.55-56). Dedikodu bir kurumda yayıldığında, çalışanlar çatışmada taraf tutmaya başlar ve iki farklı taraf oluşabilmektedir (Kartch, 2009, s.38). İttifaklar ve koalisyonlar inşa etmek, diğer bireylere zarar vermek ve intikam aramak dedikodunun fonksiyonlarındandır (Evans, 2000, s.46).

Dedikodu, grup içi veya gruplar arası rekabeti tetikleyerek, örgütün birliğini ve sürekliliği bozabilir ve üyelerin moralini olumsuz yönde etkileyebilir. Çalışanlar arasında gruplaşmalara neden olması dedikodunun etiketleyici bir süreç olduğunu göstermektedir (Noon ve Delbridge, 1993, s.32). Dedikodu, intikam amacıyla ya da küçümsenilen insanlara saldırmak için bir yöntem olarak kullanıldığında negatif hatta çok tehlikeli olabilir (Levin ve Arluke, 1987, s.22). Bu araştırmada katılımcı okul yöneticilerine göre öğrenci-öğretmen ilişkileri, öğretmenlerin haftalık ders programları, özel hayatları, maddi durumları, mesleki yeterlilikleri, kişisel özellikleri, görev ve sorumlulukları, okul yöneticileri ile ilgili olarak da öğretmenlerin kayırılması ve adaletsiz uygulamalar okullarda 
dedikodu konusu olmaktadır. Sosyal alışveriş teorisine göre dedikodu, "bilgilendirme", "ahlak dersi verme" ve "eğlence" olmak üzere üç işlevi yerine getirir (Ting-Toomey, 1979). Ancak okullarda dedikodu daha çok yanlış bilgi ve söylenti aracı olarak kabul edilmektedir (Brock ve Grady, 2009 , s.35). Sebep ne olursa olsun, dedikodu zamanı çalmakta, morali bozmakta ve iş yerinde anlaşmazlık tohumları ekmektedir (Anderson, 1995). Esas problem dedikodu yapanların, kısmi bilgiye sahip olması ve üretken olmayan yollarla onları detaylandırmasıdır. Okulda neler olup bittiği hakkındaki bilgiler yanlış yorumlandığında, dedikodu zararlı hale gelir. Okul liderleri hakkında kötü niyetli dedikodular meydana geldiğinde ise okul liderinin kariyeri tehdit altındadır ve lider bu durumdan zarar görür (Brock ve Grady, 2009, s.36).

Düşük moral, yönetim ile çalışanlar arasında güven kaybı, çalışanların iş stresinin artması, çalışma arkadaşları arasında güven kaybı, üretkenliğin azalması, kişinin ve kurumun itibarının zedelenmesi, yönetim ve paydaşlar arasında güven kaybı ve işe geç kalma ya da işe gelmeme durumunda artış dedikodu ve söylentilerin olumsuz etkileridir (DiFonzo ve Bordia, 2000; Kimmel, 2004). Söylentiler tehlikeli, zararlı ve sinsidir. Bir örgütte dedikodu yoluyla stres hızla artabilir, işbirlikçi ve dostane bir çalışma ortamını güvensiz, endişeli bir ortam haline getirebilir (Saffery, 2004, s.53). "Biz" ve "onlar" olarak bölünme, üst düzey yönetim tarafından denetimi kaybetme korkusu ve itibarın zedelenmesi dedikoduların negatif etkilerindendir (Michelson ve Mouly, 2004).

Dedikodu yönetiminde, rekabetçi bir kültür yerine işbirliğine dayalı bir kültür geliştirilmeli ve çalışanların yanlış yorumlamasına neden olabilecek bilgilendirmelerden kaçınılmalıdır (Crampton, Hodge ve Mishra, 1998). Bu araştırmada okullarda dedikodu yönetiminde katılımcıların yarısı (11/23), yönetimde şeffaflık ve açıklık olması gerektiğinin ve okul yöneticilerinin adaletli davranmasının önemine dikkat çekmişlerdir. Katılımcıların bir kısmı (6/23), kendilerine ulaşan dedikoduların yayılmaması için iyi bir sırdaş olduklarını ifade etmişlerdir. Katılımcıların bir kısmı (6/23), okullarda formal iletişimi arttırmanın dedikoduyu azaltacağını belirtmiştir. Bu sayede öğretmenlerin zamanında bilgilendirilmesi sağlanmakta ve informal iletişimin zararlı etkileri azaltılmaktadır. Hernandez (2015) yöneticilerin, bilgiyi iletmek ve yönetim takımının diğer üyeleri için destek kanallarını genişletmek amacıyla 
çeşitli iletişim kanallarını kullanarak (yazılı iletişim, yüz yüze, grup toplantıları vb.) dedikoduları yönetebileceklerini ifade etmiştir. Rayudu'ya (2009, s.340-341) göre tüm çalışanları çeşitli faaliyetler, değişiklikler, hareketler, olaylar vb. hakkında bilgilendirmek için tüm kademeleri birbirine bağlayan etkili bir iletişim sistemi kurulabilir ve bu yolla söylentinin ortaya çıkardığı zararlarla mücadele edebilir.

Gholipour, Kozekanan ve Zehtabi'ye (2011) göre dedikodu yönetiminde temel çözüm bilgilendirmedir. Kurumun politikaları, hedefleri ve planları ile ilgili konumlarına bakılmaksızın çalışanları farklı organizasyon düzeylerinde bilgilendirmek, netlik kazandırır ve şüpheleri ortadan kaldırır. Yüz yüze toplantılar ve konuşmalar yapmak da dedikoduların azaltılmasında önemli unsurlardır. DiFonzo ve Bordia'ya (2006) göre örgütsel değişim sürecinde söylentilerin fazla olması, belirsizliğin iyi yönetilmediğini gösterir. Robbins ve Judge (2014, s.169), formal iletişim yokluğunda dedikoduların daha fazla arttığını ifade etmiştir.

$\mathrm{Bu}$ araştırmada katılımcı okul yöneticileri, dedikodunun yönetiminde, yöneticilerin eleştiriye ve iletişime açık olması gerektiğini (10/23), okulda güven ortamının sağlanması gerektiğini $(4 / 23)$ ve okuldaki kararların alınmasında katılımın sağlanması gerektiğini (1/23) belirtmiştir. Zira bir okulda şeffaflık, açıklık ve güven oldukça önemlidir. Benzer şekilde Kimmel (2004, s.218) yanlış söylentilerin ortaya çıkışını azaltmak için dedikodu yönetiminde etkili örgütsel yönetimin esas kolaylaştırıcıları olarak dört özelliğin; inanılırlık, iletişim tarzı, açıklık ve güven olduğunu belirtmiştir. Ayrıca DiFonzo ve Bordia (2000) örgüt içinde güveni arttırmanın dedikodularla baş etmede etkili bir strateji olduğunu ifade etmiştir (s.182). Bir örgütte herkesin fikirlerini ifade etmesine izin veren bir kültür oluşturmak dedikoduyu azaltır (Poppen, 1968; Gholipour, Kozekanan ve Zehtabi, 2011).

Güven, insan ilişkilerinin gerekli ancak hassas bir parçasıdır. Güvenin hassaslığının anlaşılması ve okul ortamında bu hassaslığın sonuçlarının bilinmesi okul liderleri için önemlidir. Güvensizlik sadece hoş olmayan ve rahatsız edici bir çalışma ortamı yaratmakla kalmaz, aynı zamanda örgütün verimliliğini ve etkililiğini zayıflatır (Walker, Kutsyuruba ve Noonan, 2011). Yüksek güven seviyesi yüksek bilgi paylaşımı seviyesine, düşük güven seviyesi ise düşük bilgi paylaşımı seviyesine yol açmaktadır (Rutten, Blaas-Franken ve Martin, 2016). Güven iletişime dayanır. Güven; 
doğru bilgi sağlamak, kararlar için açıklamalar yapmak, samimiyet ve uygun açılık göstermek gibi iletişime dayalı davranışların bir sonucudur. Güven ayrıca planlı örgütsel iletişimle bağlantılıdır (Gillis, 2006, s.49). Güvensizlik ise söylenti ve dedikodu ile bağlantılıdır. Güven, söylentinin yayılma sıklığ 1 ile negatif şekilde ilişkilidir (DiFonzo ve Bordia, 2007, s.186-188). Buna bağlı olarak güven, dedikodu ve söylentilere ket vurmaktadır (DiFonzo ve Bordia, 1998).

Örgüt içinde çalışanların sorun ve isteklerini yöneticilere kolayca iletebilecek çift yönlü bir iletişim sistemi kurulmalıdır (Elma ve Demir, 2003, s.159). Okulda haberleşmenin sınırlı olması, öğretmenlere gerekli bilgilerin zamanında iletilmemesi, yöneticiyi bilgilendirmek için etkili bir iletişim sisteminin olmaması çatışmaya neden olabilir. Sorunların yerinde çözümü yoluyla yönetici çatışmaları yönetebilir (Erdoğan, 2000, s.128130). Bu nedenle yöneticiler, açık bir iletişimin olduğu örgütsel iklimin yaratılmasında önemli rol oynarlar (Çalık, 2003, s.94). Örgütlerde, çalışanlara adaletle ilgili hoşnutsuzluklarını tartışabilmeleri için iletişim kanalları açık tutulmalıdır. Eğitim liderlerinin geribildirime açık olmaları ve etkili şikâyet prosedürlerine sahip olmaları, örgütler için gereklidir (Dijkstra, Beersma ve van Leeuwen, 2014). Kendilerine güvenen etkili yöneticiler, çalışanların olumsuz eleştirilerini dinlerler (Özden, 2008, s.114). Böylece örgüt içinde etkili bir iletişimin oluşturulup oluşturulmadığını geri bildirim yoluyla anlayabilirler (Çalık, 2003, s.94-95).

$\mathrm{Bu}$ araştırmanın bulgularına göre katılımcı okul yöneticilerinin bir kısmı (10/23), okulda yaşanan gruplaşmalar ve çatışmalarla ilgili olarak özellikle grup liderleriyle iletişime geçip arabuluculuk rolü üstlenerek dedikoduları yönetmeye çalıştıklarını belirtmiştir. Karip'e (2015) göre arabulucu, taraf olmayan bir kişinin çatışma konusuyla ilgilenip, tarafların söz konusu çatışma ile ilgili çözüme varmaları için çabalayan kişidir (s.141). Yönetici, kurumda çatışma olduğunda, tarafların bunu sona erdirmelerini ister. Hatta yönetici, tarafları cezalarla tehdit edebilir. Ancak yöneticinin bu müdahalesi, tarafların çatışmasını sona erdirmeyeceği gibi, yöneticiye karşı da tepki oluşmasına sebep olabilir. Sonuçta iki taraflı olan çatışmaya üçüncü bir taraf eklenebilir (s.149).

Katılımcı okul yöneticilerinin bir kısmı (6/23), bazı durumlarda dedikoduları göz ardı ederek dedikoduları yönettiklerini ifade etmiştir. Çok etkili bir strateji olmasa da, zayıf dedikoduları yok saymak (Kimmel, 2004, 
s.169) ve söylentiyi görmezden gelmek (DiFonzo ve Bordia, 2000, s.182), dedikodu ve söylentilerin olumsuz etkilerinin azaltılmasını sağlamaktadır. Böylece söz konusu sorunlara zamanla daha uygun bir çözüm bulunabilir ve fikir birliği sağlanacak bir seçenek ortaya çıkabilir. Bu nedenle yöneticiler bazen sorunların çözümünü erteleyebilirler (Başaran, 2004, s.345).

Dedikodu tamamen ortadan kaldırılamadığından, yönetim onu sürekli izlemek durumundadır. Örneğin zararlı bir yarı-gerçek bilgi dolaşmaya başlarsa, yönetim doğru bilgileri vermek için hızlıca harekete geçmek zorundadır. Doğru bilgiyi yaymak ise grup liderlerine bilgi vermek, bilgilendirme toplantıları düzenlemek, duyuru panolarına duyurular asmak, bültenleri ve talimatları dağıtmak suretiyle yapılabilir. Ĕger konu oldukça ciddiyse, acil bir toplantı yapılabilir (Rai ve Rai, 2008, s.56). Bu araştırmada katılımcı okul yöneticilerinin büyük bir kısmı (18/23), dedikodu yapan kişileri uyararak ve dedikoduyu kontrol altına almak suretiyle dedikoduları yönettiklerini belirtmişlerdir.

$\mathrm{Bu}$ araştırmada katılımcı okul yöneticilerinin bazıları (4/23), dedikoduların yönetiminde zamanında bilgilendirmenin, var olan dedikoduları azaltacağını belirtmiştir. Kimmel'e (2004, s.169) göre gerçek bilgi ve doğruların paylaşımı dedikoduları önleme stratejilerinden biridir. Gerçekler ile söylentilerin aksini ispat etmek, dedikoduların kontrolünde uygulanacak adımlardan biridir (Kumar ve Gopinadhan, 2009, s.49). Çünkü dedikodu ve söylentiler, doğru bilginin mevcut olmaması durumlarında ortaya çıkmaktadır (Pezzo ve Beckstead, 2006). Gerçeği yüz yüze zamanında paylaşmak söylenti ile baş etmek için esas alınan etkili bir yoldur (olumlu reklam). Bu yaklaşım, özellikle örgütün her bir üyesinin yanlış anlamalarını gidermek gerektiğinde, hız ve doğruluk açısından avantajlıdır (Akande ve Odewale, 1994).

Okuldaki öğretmenlerin dedikodular nedeniyle farklı gruplara ayrılması, iletişimin çoğunlukla dedikodular kanalıyla sağlanması ve daha da kötüsü bunun bir alışkanlık haline gelmesi bir kurumun varlığını temelden zedeleyen ve çürüten bir durumdur. Dedikodu ve söylentilerle baş etme stratejisi her ne olursa olsun, bir okulda dedikodu ve söylentileri yönetmede okul yöneticilerine önemli görevler düşmektedir. $\mathrm{Bu}$ bağlamda okul yöneticilerinin mesleki bilgi ve yeterliliğini artırıcı hizmet içi eğitimlerin yapılması önerilmektedir. 
EXTENDED ABSTRACT

\title{
Opinions of School Administrators on Gossip and Gossip Management
}

\author{
Faruk Levent - Gözde Türkmenoğlu
}

Marmara University

Gossip have some definitions, such as, "a conversation about a third person who is not participating in the conversation" (Wittek and Wielers, 1998 ) and the process of informally communicating value-laden information about members of a social setting" (Noon and Delbridge, 1993, p.25). Gossip is divided into positive and negative (Turner, Mazur, Wendel and Winslow, 2003). Positive gossip is information about socially approved behavior. In this case, gossip acts as a positive social sanction. Negative gossip is information about socially inappropriate behavior and people can use gossip as a negative social sanction (Levin, Mody-Desbareau and Arluke, 1988).

Rumor can be defined as "gossip information that is communicated without secure standards of evidence being present". Rumor is the unverified and untrue part of the gossip. Rumor usually arises because a given information is not only interesting but also ambiguous. The rumor changes as it passes from one individual to another, since it relies on the interest and uncertainty of information. The rumor depends on the detailing. It means that individuals add new details to the information on the basis of their feelings and thoughts (Kumar and Gopinadhan, 2009, p. 48). The effects of the rumor; lowered employee morale, loss of trust between management and staff, increased employee stress (Kimmel, 2004, p. 222).

Gossip which constitutes an important part of informal communication, is an indispensable form of communication in an organization. The gossip is a complement of formal communication. In this context, it must be properly managed. There is no possibility to eliminate rumors completely. For this reason, the school administrators should manage the gossip networks effectively in the organization and turn the gossip quickly 
into an advantage. Therefore, the school administrators must improve his/her communication skills.

Schools are organizations where human relations are intense. Gossip can be made between teachers, students, parents, servants and other staff in the schools.

Rumor or gossip is an immensely complex activity. The informal communication network or gossip is a constantly changing social interaction not limited by formal structures. The aims or functions of gossip include information, influence and entertainment. Besides, there are different types of rumor including wish fulfilment, anxiety, anticipatory, and aggressive rumors. And, finally, the role of context, as well as certain personality characteristics of individuals all impact on rumor /gossip. This indicates that a comprehensive understanding of this phenomenon within organizations requires a deep knowledge of a range of different factors (Michelson and Mouly, 2004). In this context, the purpose of this study was to examine the opinions of school administrators on the gossip and gossip management in schools.

\section{Method}

This research was designed with phenomenology, which is one of the qualitative research methods. In order to determine the study group of the research, maximum variation sampling method, which is one of the purposeful sampling methods, was used. The study group of the research was composed of 23 school administrators who work in public schools in the province of Tekirdağ, Çorlu. The data on this research were collected in 2016-2017 academic year. A semi-structured interview form was developed to collect data from school administrators in the study group. The interview questions which were developed on the basis of the literature and experts views, were asked to find out the school administrators' opinions on the gossip and gossip management. The school administrators' answers were noted down. The data obtained from the research were analyzed by content analysis technique. As a result of content analysis, interview data were coded under the themes. 


\section{Results}

The findings from this study can be summarized as follows; most of the participants in the research, explained gossip as negative talk behind someone's back. The school administrators who have interviewed stated that student-teacher relations, weekly course schedule and professional competences were mostly subject of gossip. Although the school administrators have negative consequences for gossip, there are some positive results. Participants looking gossip as positively think that gossip is a source of self-criticism, also gossip allows problems to be noticed and gossip is a fun activity. Regarding the negative results of gossip, the participant school administrators stated that gossip causes groupings in the school and leads to low performance/motivation of teachers, creates a distrust environment in the school and causes teachers to be discredit. School administrators' opinions on the management of gossip can be described as follows; to warn the gossipers, transparency/openness in management, openness to criticism, mediation, keeping secrets, ignoring some rumors, to increase formal communication, to be fair, to create an atmosphere of trust, to inform at the right time, to participate in consultations/decisions and to reduce leisure time.

\section{Kaynakça / References}

Akande, A., ve Odewale, F. (1994). One more time: How to stop company rumours. Leadership and Organization Development Journal, 15(4), 2730.

Anderson, B. (1995). Less gossip, better schools. The Education Digest, 61(4), 19-22.

Aydın, M. (2007). Eğitim yönetimi. Ankara: Hatiboğlu Yayıncılık.

Ball, S. J., ve Vincent, C. (1998). I heard it on the grapevine: Hot knowledge and school choice. British Journal of Sociology of Education, 19(3), $377-400$.

Başaran, İ. E. (2004). Yönetimde insan ilişkileri: Yönetsel davranış. Ankara: Nobel Yayıncilık. 
Ben-Ze'ev, A. (1994). The vindication of gossip. In R. F. Goodman, and A. Ben-Ze'ev (Eds) Good gossip (pp.11-24). Lawrence, KS: University Press of Kansas.

Bowditch, J. L., ve Buono, A. F. (2005). A primer on organizational behavior (6th ed.). New York: Wiley.

Brock, B. L., ve Grady, M. L. (2009). From difficult teachers...to dynamic teams. Thousand Oaks, CA: Corwin.

Burke, L. A., ve Wise, J. M. (2003). The effective care, handling, and pruning of the office grapevine. Business Horizons, 46, 71-76.

Christensen, L. B., Johnson, R. B., ve Turner, L. A. (2015). Araştırma yöntemleri desen ve analiz. Ankara: An Yayıncilık.

Crampton, S. M., Hodge, J. W., ve Mishra, J. M. (1998). The informal communication network: Factors influencing grapevine activity. Public Personnel Management, 27(4), 569-585.

Creswell, J. W. (2007). Qualitative inquiry and research design: Choosing among five approaches (2nd ed.). Thousand Oaks, CA: Sage.

Coleman, M. (2012). Interviews. In Coleman, M., Briggs, A. R. J. and Morrison, M. (eds.) Research methods in educational leadership and management, (pp. 250-266). London: Sage.

Çalık, T. (2003). Performans yönetimi: Tanımlar, kavramlar, ilkeler. Ankara: Gündüz Eğitim ve Yayıncllık.

DiFonzo, N., ve Bordia, P. (1998). A tale of two corporations: Managing uncertainty during organizational change. Human Resource Management, 37, 295-303.

DiFonzo, N., ve Bordia, P. (2000). How top PR professionals handle hearsay: Corporate rumors, their effects, and strategies to manage them. Public Relations Review, 26(2), 173-190.

DiFonzo, N., ve Bordia, P. (2006). Rumor in organizational contexts. In Donald A. Hantula (Ed) Advances in theory and methodology in social and organizational psychology. Mahwah, NJ: Laurence Erlbaum Publisher.

DiFonzo, N., ve Bordia, P. (2007). Rumor psychology: Social and organizational approaches. Washington, DC: American Psychological Association.

Dijkstra, M., Beersma, B., ve van Leeuwen, J. (2014). Gossiping as a response to conflict with the boss: alternative conflict management 
behavior? International Journal of Conflict Management, 25(4), 431454.

Drisko, J. W., ve Maschi, T. (2016). Content analysis. New York: Oxford University Press.

Dunbar, R. I. M. (2004). Gossip in evolutionary perspective. Review of General Psychology, 8(2), 100-110.

Ellwardt, L., Labianca, G., ve Wittek, R. (2012). Who are the objects of positive and negative gossip at work? A social network perspective on workplace gossip. Social Networks, 34, 193-205.

Elma, C., ve Demir, K. (2003). Yönetimde çă̆daş yaklaşımlar. Ankara: Anı Yayıncilik.

Erdoğan, İ. (2000). Okul yönetimi ve öğretim liderlĭgi. İstanbul: Sistem Yayıncilik.

Evans, T. (2000). Understanding gossip in the workplace: A case study (Unpublished doctoral dissertation). California State University Dominguez Hills, Carson.

Foster, E. K. (2004). Research on gossip: Taxonomy, methods, and future directions. Review of General Psychology, 8(2), 78-99.

Gabriels, K., ve De Backer, C. J. S. (2016). Virtual gossip: How gossip regulates moral life in virtual worlds. Computers in Human Behavior, 63, 683-693.

Gholipour, A., Kozekanan, S. F., ve Zehtabi, M. (2011). Utilizing gossip as a strategy to construct organizational reality. Business Strategy Series, 12(2), 56-62.

Gliner, J. A., Morgan, G. A., ve Leech, N. L. (2015). Uygulamada araştırma yöntemleri: Desen ve analizi bütünleştiren yaklaşım. Ankara: Nobel Akademik Yayıncilik.

Gillis, T. L. (2006). The IABC handbook of organizational communication: A guide to internal communication, public relations, marketing, and leadership. San Francisco, CA: Jossey-Bass.

Granecki, J. W. (2014). Did you hear? Gossip as a manifestation of trait aggression (Unpublished master's thesis). East Carolina University, Greenville, SC.

Hernandez, J. R. (2015). How do managers handle organizational rumors effectively, and does emotional intelligence help? A qualitative inquiry. (Unpublished doctoral dissertation). Capella University, Minneapolis. 
Kakar, U. M. (2013). Workplace gossip as a way of coping with occupational stress (Unpublished doctoral dissertation). University at Albany, New York.

Karasar, N. (2015). Bilimsel araştırma yöntemleri. Ankara: Nobel Akademik Yayıncilik.

Karip, E. (2015). Çatışma yönetimi (6. Baskı). Ankara: PegemA Yayıncılık.

Kartch, F. (2009). An ethnographic examination of gossip in a small organization: Coalitions and conflict escalation (Unpublished master's thesis). Northern Illinois University, DeKalb, Illinois.

Kimmel, A. J. (2004). Rumors and rumor control: A manager's guide to understanding and combatting rumors. Mahwah, NJ: Laurence Erlbaum Publisher.

Kumar, V. B., ve Gopinadhan, S. (2009). Psychology of human behavior at work. Mumbai: Himalaya Publishing House.

Kurland, N. B., ve Pelled, L. H. (2000). Passing the word: Toward a model of gossip and power in the workplace. The Academy of Management Review, 25(2), 428-438.

Levin, J., ve Arluke, A. (1987). Gossip: The inside scoop. New York: Plenum Press.

Levin, J., Mody-Desbareau, A., ve Arluke, A. (1988). The gossip tabloid as agent of social control. Journalism Quarterly, 65(2), 514-517.

Litman, J. A., ve Pezzo, M. V. (2005). Individual differences in attitudes towards gossip. Personality and Individual Differences, 38(4), 963980.

Merriam, S. B. (2013). Nitel araştırma desen ve uygulama için bir rehber. Ankara: Nobel Akademik Yayıncilik.

Mertens, D. M. (2010). Research and evaluation in education and psychology: Integrating diversity with quantitative, qualitative, and mixed methods. Thousand Oaks, CA: Sage.

Michelson, G., ve Mouly, V. S. (2004). Do loose lips sink ships? Corporate Communications: An International Journal, 9(3), 189-201.

Noon, M., ve Delbridge, R. (1993). News from behind my hand: Gossip in organizations. Organization Studies, 14(1), 23-36.

Özden, Y. (2008). Eğitimde yeni değerler. Eğitimde dönüşüm. Ankara: PegemA Yayıncilik. 
Peters, K., ve Kashima, Y. (2015). Bad habit or social good? How perceptions of gossiper morality are related to gossip content. European Journal of Social Psychology, 45(6), 784-798.

Pezzo, M. V., ve Beckstand, J. W. (2006). A multilevel analysis of rumor transmission: Effects of anxiety and belief in two field experiments. Basic and Applied Social Psychology, 28(1), 91-100.

Poppen, W. A. (1968). Communication problems in the schools: Myths and realities. Peabody Journal of Education, 45(4), 220-224.

Rai, U., ve Rai, S. M. (2008). Effective communication. Mumbai: Himalaya Publishing House.

Rayudu, C. S. (2009). Communication. Mumbai: Himalaya Publishing House.

Robbins, S. P., ve Judge, T. A. (2014). Essentials of organizational behavior (Twelfth Edition). New Jersey: Pearson.

Rutten, W., Blaas-Franken, J. ve Martin, H. (2016). The impact of (low) trust on knowledge sharing. Journal of Knowledge Management, 20(2), 199-214.

Saffery, M. (2004). Corporate rumors: Causes, formation, and refutation (Unpublished master's thesis). University of Southern California, Los Angeles.

Ting-Toomey, S. (1979). Gossip as a communication construct. Retrieved from https://eric.ed.gov/?id=ED224069 (05.03.2017).

Turcotte, D. (2012). Gossip and the group: a self-categorization perspective (Unpublished doctoral dissertation). Claremont Graduate University, Claremont, CA.

Turner, M. M., Mazur, M. A., Wendel, N., ve Winslow, R. (2003). Relational ruin of social glue? The joint effect of relationship type and gossip valence on liking, trust, and expertise. Communication Monographs, 70(2), 129-141.

Türk Dil Kurumu. (2018). Güncel Türkçe sözlük. http://www.tdk.gov.tr adresinden 5 Mart 2018' de elde edilmiştir.

Walker, K., Kutsyuruba, B., ve Noonan, B. (2011). The fragility of trust in the world of school principals. Journal of Educational Administration, 49(5), 471-494.

Wert, S. R., ve Salovey, P. (2004). A social comparison account of gossip. Review of General Psychology, 8, 122-137. 
Wittek, R., ve Wielers, R. (1998). Gossip in organizations. Computational and Mathematical Organization Theory, 4(2), 189-204.

Yıldırım, A., ve Şimşek, H. (2013). Sosyal bilimlerde nitel araştırma yöntemleri. Ankara: Seçkin Yayıncılık.

\section{Kaynakça Bilgisi / Citation Information}

Levent, F. ve Türkmenoğlu, G. (2019). Okul yöneticilerinin dedikodu ve dedikodu yönetimine ilişkin görüşleri. OPUS-Uluslararası Toplum Araştırmaları Dergisi , 10(17), 787-814. DOI: 10.26466/opus.518272 